\title{
Distinct protein degradation mechanisms mediated by Cul1 and Cul3 controlling Ci stability in Drosophila eye development
}

\author{
Chan-Yen Ou, ${ }^{1}$ Yi-Fan Lin, ${ }^{1,2}$ Ying-Jiun Chen, ${ }^{1}$ and Cheng-Ting Chien ${ }^{1,2,3}$ \\ ${ }^{1}$ Institute of Molecular Biology, Academia Sinica, Taipei, Taiwan; ${ }^{2}$ Institute of Molecular Medicine, College of Medicine, \\ National Taiwan University, Taipei, Taiwan
}

\begin{abstract}
The ubiquitin-like protein, Nedd8, covalently modifies members of the Cullin family. Cullins are the major components of a series of ubiquitin ligases that control the degradation of a broad range of proteins. We found that Nedd8 modifies Cul1 in Drosophila. In Drosophila Nedd8 and Cul1 mutants, protein levels of the signal transduction effectors, Cubitus interruptus (Ci) and Armadillo (Arm), and the cell cycle regulator, Cyclin E (CycE), are highly accumulated, suggesting that the Cul1-based SCF complex requires Nedd8 modification for the degradation processes of $\mathrm{Ci}$, Arm, and $\mathrm{CycE}$ in vivo. We further show that two distinct degradation mechanisms modulating $\mathrm{Ci}$ stability in the developing eye disc are separated by the morphogenetic furrow (MF) in which retinal differentiation is initiated. In cells anterior to the MF, Ci proteolytic processing promoted by PKA requires the activity of the Nedd8-modified Cul1-based SCF ${ }^{\text {slimb }}$ complex. In posterior cells, Ci degradation is controlled by a mechanism that requires the activity of Cul3, another member of the Cullin family. This posterior $\mathrm{Ci}$ degradation mechanism, which partially requires Nedd8 modification, is activated by Hedgehog $(\mathrm{Hh})$ signaling and is PKA-independent.
\end{abstract}

[Keywords: Nedd8; Cullins; SCF; Ci; protein degradation; eye development]

Received May 31, 2002; revised version accepted July 26, 2002.

Ubiquitin-mediated protein degradation mechanisms control the stability of various proteins that are essential for cellular function. Nedd8 is a ubiquitin-like small protein modifier. The Nedd8 conjugation process, called neddylation, is similar to ubiquitination. Neddylation utilizes the E1 activating-enzyme complex composed of two subunits, APP-BP1 and UBA3, and the E2 conjugating-enzyme, UBC12 (Yeh et al. 2000). The only known substrates of neddylation are Cullin family proteins, Cul1, Cul2, Cul3, Cul4A, Cul4B, and Cul5, which have been shown to be modified by Nedd 8 in mammalian cells (Osaka et al. 1998; Hori et al. 1999). Cullins directly interact with Roc1, a Ring finger protein, and the CullinRoc1 complex comprises the core module of a series of ubiquitin E3 ligases, which confer substrate specificity and therefore regulate the degradation process (Kamura et al. 1999b; Ohta et al. 1999; Seol et al. 1999; Skowyra et al. 1999). Among Cullins, many studies focused on Cul1, an essential component of the SCF complex which functions as ubiquitin E3 ligase. The SCF complex consists of

${ }^{3}$ Corresponding author.

E-MAIL ctchien@ccvax.sinica.edu.tw; FAX 886-2-2782-6085.

Article and publication are at http://www.genesdev.org/cgi/doi/10.1101/ gad.1011402. core subunits: $\underline{\mathrm{C}} \mathrm{ul1} / \mathrm{Cdc53}$, $\mathrm{Skp1}$, Roc1/Hrt/Rbx1, and a substrate-recognition $\underline{F}$-box protein. Cull functions as a scaffold protein within the SCF complex; the N-terminal domain of Cul1 interacts with the adaptor protein Skp1 that links with the F-box protein, and the C-terminal domain interacts with Roc1 and the ubiquitin E2 enzyme.

In vitro, neddylation of Cull is required for ubiquitination of $\mathrm{I}_{\kappa} \mathrm{B} \alpha$ and $\mathrm{p} 27^{\mathrm{Kip} 1}$ (Morimoto et al. 2000; Podust et al. 2000; Read et al. 2000). In addition, neddylation enhances E2-ubiquitin recruitment to SCF (Kawakami et al. 2001). In fission yeast, Nedd8 is essential for the SCFmediated degradation of Rum-1, a cyclin-dependent kinase inhibitor (Osaka et al. 2000). In Arabidopsis thaliana, the Nedd8 pathway is required for SCF-mediated Auxin response (Pozo et al. 1998; Schwechheimer et al. 2001). In mice deficient for $U B A 3$, a subunit of the E1 enzyme in neddylation, embryonic development is aberrant, with accumulation of two putative SCF substrates, $\beta$-catenin and cyclin E (CycE; Tateishi et al. 2001).

In the SCF complex, F-box proteins convey substrate specificity by direct interaction with substrates for degradation. Many F-box proteins have been characterized in metazoans, and increasing numbers of specific targets for F-box proteins are being found (Deshaies 1999). 
Among them, the Drosophila F-box protein Slimb and its mammalian homolog $\beta$-TrCP are well characterized for their target specificity (for review, see Maniatis 1999). The specific targets for Slimb/ $\beta$-TrCP are $\mathrm{pI} \mathrm{B} \alpha$ in the Dorsal/NFkB pathway, Arm/ $\beta$-catenin in the $\mathrm{Wg} / \mathrm{Wnt}$ pathway, and $\mathrm{Ci} / \mathrm{Gli}$ in the Hedgehog $(\mathrm{Hh})$ pathway (Jiang and Struhl 1998; Yaron et al. 1998; Spencer et al. 1999; Winston et al. 1999).

The Hh pathway controls growth and pattern formation in many developmental processes in both vertebrates and invertebrates (for review, see Ingham and McMahon 2001). The Hh signal is transmitted through a receptor complex consisting of Patched (Ptc) and Smoothened (Smo). In the absence of Hh, Ptc inhibits Smo activity, and the effector Cubitus interruptus (Ci) is phosphorylated by PKA, leading to the proteolysis of $\mathrm{Ci}$, which is converted into Ci75 with the $\mathrm{C}$ terminus truncated. Ci75 functions as a transcriptional repressor in the Hh signaling pathway. Upon binding to Ptc, Hh relieves Smo from its repression state. Activated Smo mediates signaling to prohibit proteolytic processing of $\mathrm{Ci}$. The intact full-length $\mathrm{Ci}\left(\mathrm{Ci}^{\mathrm{FL}}\right)$ functions as a transcriptional activator for expression of target genes of the Hh pathway.

In Drosophila, Hh signaling functions in patterning the A/P compartments in developing tissues such as embryonic segments and wing and leg imaginal discs. In development of the eye imaginal disc, Hh signaling is a major driving force of the retinal differentiation wave, the morphogenetic furrow (MF), which is caused by transient constriction in cell apical surface (Heberlein et al. 1993; Ma et al. 1993). The MF progresses anteriorly from the posterior margin of the eye disc during the third instar larval and early pupal stages (Ready et al. 1976). Anterior to the advancing $\mathrm{MF}$, cells are proliferating, whereas posterior cells differentiate sequentially into photoreceptor, cone, or pigment cells which produce and secrete $\mathrm{Hh}$ proteins. Transduction of $\mathrm{Hh}$ signaling in the $\mathrm{MF}$ is revealed by the accumulation of $\mathrm{Ci}^{\mathrm{FL}}$, which activates expression of target genes such as $d p p$ and atonal in the MF (Heberlein et al. 1993; Dominguez and Hafen 1997; Greenwood and Struhl 1999). The induced MF cells soon differentiate and produce Hh proteins for further induction of more anterior cells, thus making the MF move forward.

The effect of neddylation on a broad spectrum of E3 ligases remains largely unknown. To investigate the role of neddylation in protein degradation control during developmental processes, we identified and analyzed Nedd8 and Cul1 mutants in Drosophila. Our results suggest that neddylation is required for Cull-mediated protein downregulation of the signaling pathway effectors $\mathrm{Ci}$ and Armadillo (Arm) and the cell cycle regulator CycE. Using the developing eye disc as a model system to study the regulation of $\mathrm{Ci}^{\mathrm{FL}}$ stability, we found that there is mechanistic difference in controlling $\mathrm{Ci}^{\mathrm{FL}}$ stability between anterior and posterior cells separated by the MF. Whereas the Cull-based SCF ${ }^{\text {Slimb }}$ complex controls $\mathrm{Ci}^{\mathrm{FL}}$ stability in anterior cells, a Cul3-dependent protein degradation mechanism controls $\mathrm{Ci}^{\mathrm{FL}}$ stability in posterior cells. We further investigated the differences between these two protein degradation mechanisms.

\section{Results}

Effects of Nedd8 mutations on growth and protein stability

Nedd8 is highly conserved from yeast to mammals (Fig. 1A). We identified several Nedd8 alleles in Drosophila, including two null alleles Nedd $8^{A N O 15}$ and Nedd8 ${ }^{A N O 24}$ that were used in the present study (see Materials and Methods). The Nedd8 null mutants were growth-arrested in the first-instar larval stage and died within several days without further growth (Fig. 1B). We generated mutant clones to analyze Nedd8 loss-of-function phenotypes, and observed in the adult flies very few Nedd ${ }^{A N O 15}$ mutant cells (Fig. 1D,F), whereas in control experiments, large $\mathrm{Nedd} 8^{+}$clones were frequently recovered (Fig. 1C,E). Nedd8 mutant clones of small size, however, were present in the developing discs, suggesting that Nedd8 mutant cells were defective in proliferation and survival.

To study the relationship between Nedd8 and the Fbox protein Slimb-mediated protein degradation, we examined the protein stability for substrates of Slimb in Nedd8 mutant cells. As shown in Figure 1G-I and J-L, respectively, Nedd8 mutant cells in developing wing discs accumulated high levels of full-length $\mathrm{Ci}\left(\mathrm{Ci}^{\mathrm{FL}}\right)$ and Arm proteins, phenotypes identical to those observed in the slimb mutants (Jiang and Struhl 1998). In Drosophila embryonic development, the signaling pathway mediated by the NFkB homolog Dorsal is required for patterning the dorsoventral identity. Accumulation of $\mathrm{pI \kappa \textrm {B } \alpha /}$ Cactus inhibits Dorsal activation, leading to repression of the downstream target gene, twist, an effect that has been observed in slimb mutants (Spencer et al. 1999). We examined twist expression in embryos laid by $\mathrm{Nedd} 8^{\mathrm{ANO} 15} / \mathrm{Nedd} 8^{203}$ females in which $\mathrm{Nedd} 8^{203}$ is a hypomorphic allele (see Materials and Methods). In such embryos, the twist expression domain was reduced along the dorsoventral axis and often found missing in many cells (Fig. 1Q), revealing a requirement for Nedd8 in Dorsal signaling.

We further tested whether Nedd 8 affects the protein level of CycE that is regulated by the F-box protein, Archipelago (Ago; Moberg et al. 2001). As shown in Figure $1 \mathrm{M}-\mathrm{O}, \mathrm{CycE}$ accumulated in Nedd8 mutant cells in the eye disc. Our results suggest that Nedd8 might affect the stability of a broad range of proteins through F-box proteins in flies.

Consequence of $\mathrm{Ci}^{F L}$ accumulation in Nedd8 mutant cells in the developing eye disc and its response to Hh signaling

The Drosophila eye imaginal disc is an excellent model system for developmental study. Cells are undifferentiated and dividing randomly anterior to the MF, and cells posterior to the MF are differentiating into different 
A

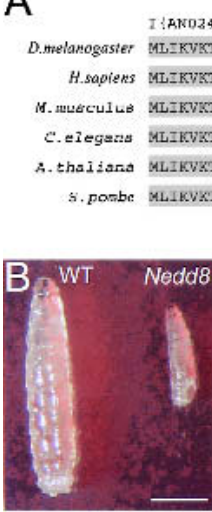
W

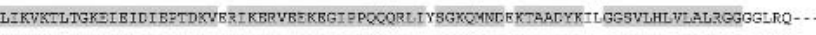

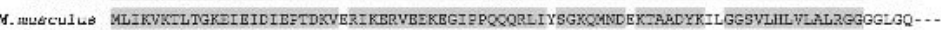

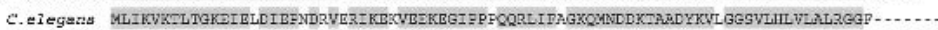

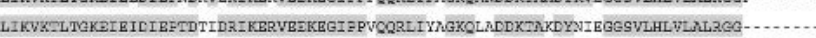

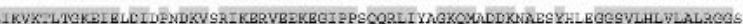
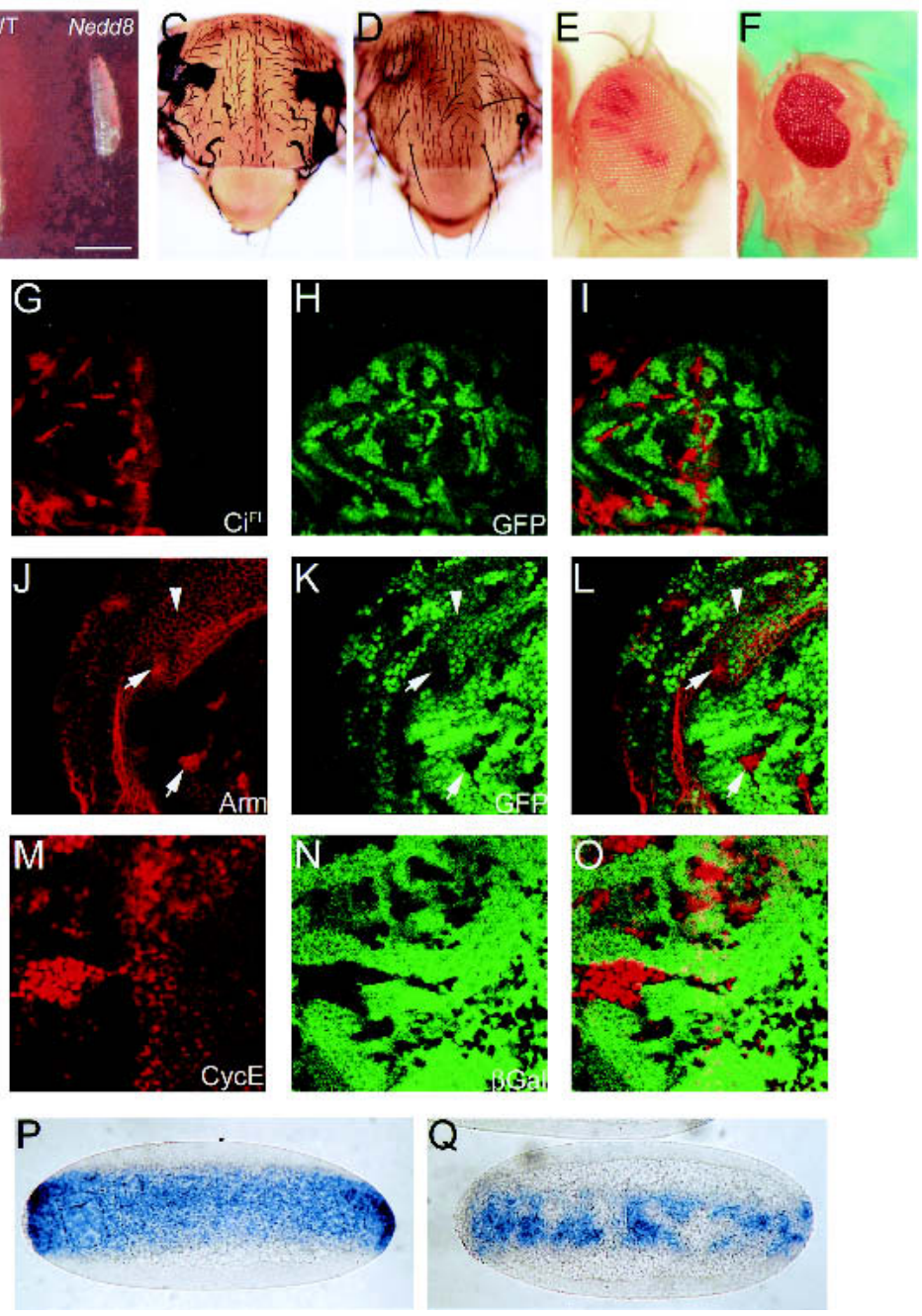

Figure 1. Conservation of Nedd8 in evolution and Drosophila Nedd8 mutant phenotypes. (A) Sequence comparison of Nedd8. Drosophila Nedd8 shares $88 \%-98 \%$ identity to other Nedd 8 from yeast to mammals. Also indicated are the point mutations in Nedd8 $8^{A N O 24}$ and Nedd8 ${ }^{A N O 15}$ alleles. Conceptually, Nedd $8^{A N O 15}$ encodes a C-terminus-truncated protein by a nonsense mutation at aa 49 . Thus, Gly76, the essential residue required for conjugation to the substrate protein (Wada et al. 1998), was missing in this mutant. In Nedd8 ${ }^{A N O 24}$, the translation start codon was replaced by a missense mutation. $(B)$ The 4-d-old larvae of wild-type (left) and Nedd $8^{A N O 24}$ (right). Note growth of the Nedd $8^{A N O 24}$ larva was arrested in the first instar stage. Bar, $0.5 \mathrm{~mm} .(C-F)$ The growth and survival defect of Nedd 8 mutant cells. $(C, D)$ The adult nota of $w f h s-F L P ;+F R T^{40 A} /$ M2(Z)f $f^{+30 b} F R T^{40 A}(C)$ and $w f$ hs-FLP; Nedd $8^{A N 015}$ $F R T^{40 A} / M 2(Z) f^{+30 b} F R T^{40 A}(D)$. (C) Almost all cells in the adult notum are marked with forked (note curly forked bristles) compared to $D$, in which no Nedd $8^{A N 015}$ mutant clones can be observed. $(E, F)$ The adult eyes of $w$ ey-FLP; $+F R T^{40 A} / c 12 L 3 p\left[\mathrm{w}^{+30 C}\right]$ FRT $T^{40 A}(E)$ and $w$ ey-FLP; Nedd $8^{A N O 15}$ FRT $^{40 A} /$ cl2L3 $p\left[w^{+30 C}\right] F R T^{40 A}(F)$. The wild-type clones containing white ommatidia occupy almost the whole eye in $E$, compared to $F$ in which Nedd8 $8^{A N O 15}$ clones (marked by white ommatidia) are absent, leaving a defective eye that contains only Nedd $8^{\text {ANO15/+ }}$ cells in red ommatidia. $(G-Q)$ Accumulation of $\mathrm{Ci}^{\mathrm{FL}}$, Arm, and $\mathrm{CycE}$, and disruption of twist mRNA expression in Nedd8 mutant cells. The wing $(G-L)$ or eye discs $(M-O)$ carrying Nedd8 mutant clones marked by the lack of GFP $(H, K)$ or $\beta$-galactosidase expression $(N)$. Accumulation of $\mathrm{Ci}^{\mathrm{FL}}$ (red in $G, I$ ) appears only in mutant clones located in the anterior compartment of the wing disc (for imaginal discs in this and following figures, anterior is to the left). Accumulation of Arm (red in $J, L$ ) appears in the cytosol of Nedd8 mutant cells (arrows), in contrast to the cell surface-associated Arm in wild-type cells (arrowheads). ( $M, O)$ Accumulation of CycE is also detected in the Nedd8 mutant clones in the eye disc. $(P, Q)$ In situ hybridization of twist mRNA in wildtype embryos $(P)$ and Nedd8 mutant embryos laid by Nedd8 ${ }^{A N 015} / N^{2} d d 8^{203}$ females (Q). types of cells. Thus, we can observe Nedd8 phenotypes in cells of different differentiation states in a single eye disc. The Hh pathway is the major signaling pathway in eye development, and the protein level of its effector $\mathrm{Ci}$ is tightly regulated in Drosophila (Ingham and McMahon 2001). We focused our studies on how Nedd8 regulates the $\mathrm{Ci}^{\mathrm{FL}}$ level in the Hh pathway and the effects of $\mathrm{Ci}$ upregulation on eye development. We found that in the Nedd8 clones that located anterior to the $\mathrm{MF}, \mathrm{Ci}^{\mathrm{FL}}$ accumulated to a level identical to that in the MF cells that transduce the Hh signaling pathway (Fig. 2A,B, arrows). Accumulation of $\mathrm{Ci}^{\mathrm{FL}}$ also existed in posterior mutant cells that located proximally (Fig. 2A,B, arrowheads) but not distally (Fig. 2A,B, asterisks) to the MF. $\mathrm{Ci}^{\mathrm{FL}}$ accumulation in Nedd8 mutant cells was not caused by an increase in the ci transcription level, be- cause expression of ci-lac $Z$ that recapitulates endogenous ci expression (Jiang and Struhl 1998) remained constant in Nedd8 mutant cells (Fig. 2C,D), indicating that posttranscriptional defects resulted in $\mathrm{Ci}^{\mathrm{FL}}$ accumulation.

Elevated $\mathrm{Ci}^{\mathrm{FL}}$ levels caused anterior Nedd8 mutant cells to adopt MF fate precociously. Nedd8 mutant cells constricted in the apical surface, as revealed by the intensified phalloidin staining (Fig. 2F), and expressed the Hh-target gene, $d p p$, as detected by the expression of dpp-lacZ reporter gene (Fig. 2G; Blackman et al. 1991). Furthermore, the early photoreceptor marker, Atonal, was induced (Fig. 2H, arrows). These phenotypes were observed only in mutant cells abutting the MF anteriorly, suggesting that accumulated $\mathrm{Ci}^{\mathrm{FL}}$ in Nedd8 mutant cells was able to respond to Hh signaling. 
Ou et al.
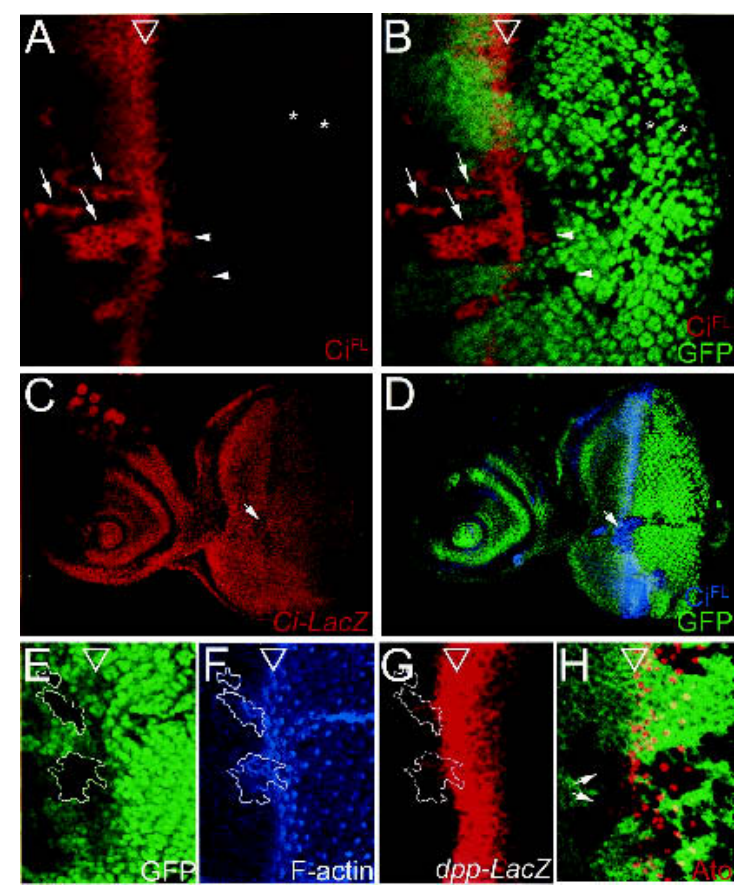

Figure 2. Nedd8 affects transduction of the Hh pathway in Drosophila eye development. $(A-D)$ The $\mathrm{Ci}^{\mathrm{FL}}$ protein, but not $c i$ expression, is upregulated in the Nedd8 mutant cells (revealed by the lack of GFP expression, in green). ( $A, B)$ A late third-instar eye disc containing Nedd8 mutant clones and stained by anti$\mathrm{Ci}^{\mathrm{FL}}$ antibody (2A1) in red. The open arrowheads mark the position of the MF in this and following figures. In the mutant cells anterior to the $\mathrm{MF}, \mathrm{Ci}^{\mathrm{FL}}$ accumulation (arrows) reaches a level identical to that observed in the MF where Hh signaling is fully induced. In the posterior mutant cells, $\mathrm{Ci}^{\mathrm{FL}}$ accumulation is persistent at a lower level abutting the MF (arrowheads) and not detected in more posterior cells (asterisks). Note that the anterior clones are obviously larger than the posterior clones, suggesting a survival defect in the Nedd8 mutant cells. $(C, D)$ A late third-instar eye disc containing Nedd8 mutant clones and double stained for ci-LacZ expression in red $(C)$ and $\mathrm{Ci}^{\mathrm{FL}}$ in blue $(D)$. (C) The ci-LacZ expression level is ubiquitous throughout the whole eye disc, and remains unchanged in the Nedd8 mutant clones $(C$, arrow $)$, in which the $\mathrm{Ci}^{\mathrm{FL}}$ protein accumulates $\left(D\right.$, arrow). $(E-H)$ Accumulated $\mathrm{Ci}^{\mathrm{FL}}$ responds to $\mathrm{Hh}$ signaling to induce MF fate in Nedd8 mutant clones. $(E-G)$ A late thirdinstar eye disc containing Nedd8 mutant clones was double stained for F-actin in blue $(F)$ and $d p p-L a c Z$ in red $(G)$. (E) The Nedd8 mutant clones are marked by the lack of GFP expression and outlined by a white line in $E-G$. (F) F-actin staining (blue) by phalloidin shows that the Nedd8 mutant cells constrict precociously. $(G)$ Expression of $d p p-1 a c Z$ (red) is induced in the mutant cells abutting the MF anteriorly. $(H)$ In the Nedd 8 mutant clones, as shown by lack of arm-lacZ expression (green), expression of the proneural protein Atonal (red) is induced (arrows).

\section{Nedd8-mediated $\mathrm{Ci}^{F L}$ processing is downstream of Smo signaling and PKA phosphorylation}

Although $\mathrm{Ci}^{\mathrm{FL}}$ accumulation in Nedd8 cells could result from a defect in the machinery controlling $\mathrm{Ci}^{\mathrm{FL}}$ protein processing, it was equally possible that $\mathrm{Ci}^{\mathrm{FL}}$ accumulation could be caused by the activation of Hh signaling. For example, smo has been shown to be under posttran- scriptional regulation by $\mathrm{Hh}$ signaling (Alcedo et al. 2000; Denef et al. 2000; Ingham et al. 2000). Therefore, Nedd8 activity could have affected the protein stability of Smo, leading to signal activation and $\mathrm{Ci}^{\mathrm{FL}}$ accumulation. To test whether the effect of $N e d d 8$ on $\mathrm{Ci}^{\mathrm{FL}}$ processing is dependent on $s m o$, we generated $s m o^{3}$ and Nedd8 double mutant clones in the eye disc. When the double mutant clones were located anterior to the MF, the level of $\mathrm{Ci}^{\mathrm{FL}}$ accumulation was indistinguishable from that in the Nedd8 mutant clones (cf. arrows in Figs. $2 \mathrm{~A}$ and $3 \mathrm{~A})$. As a control, anterior $s m o^{3}$ clones failed to enhance $\mathrm{Ci}^{\mathrm{FL}}$ accumulation (Fig. 3C,D). This result indicated that Nedd8-mediated $\mathrm{Ci}^{\mathrm{FL}}$ processing was independent of smo. $\left(\mathrm{Ci}^{\mathrm{FL}}\right.$ accumulation in posterior cells is described below.)

Ci protein processing is known to depend on the phosphorylation status of $\mathrm{Ci}^{\mathrm{FL}}$ by PKA /Chen et al. 1998; Price and Kalderon 1999). The level of $\mathrm{Ci}^{\mathrm{FL}}$ is downregulated when PKA is constitutively activated by the expression of its catalytic subunit (UAS- $C^{\star}$; Li et al. 1995). Therefore, we examined the functional relationship between PKA activity and Nedd8 modification. When the $U A S-C^{\star}$ transgene was driven by eq-GAL4 for misexpression in the equator region of the eye disc, as visualized by the coexpressed GFP (green in Fig. 3E), the level of $\mathrm{Ci}^{\mathrm{FL}}$ in the equator region was reduced (Fig. $3 \mathrm{~F}$ ), consistent with the observations that PKA phosphorylates $\mathrm{Ci}$ and promotes $\mathrm{Ci}$ proteolysis. We then generated Nedd8 mutant clones in the equator region where PKA is constitutively activated. In Nedd8 clones that overlapped the eq-GAL4 expression domain, $\mathrm{Ci}^{\mathrm{FL}}$ accumulated to a high level (Fig. 3G, arrow), identical to the level in the Nedd8 clone located externally to the eq-GAL4 expression domain (Fig. 3G, arrowhead). These results indicated that $\mathrm{Ci}^{\mathrm{FL}}$ downregulation by PKA activity requires Nedd8 activity, and the effect of the Nedd8 pathway on $\mathrm{Ci}^{\mathrm{FL}}$ processing is unlikely to be mediated through modulation of PKA activity.

\section{Nedd8 modifies Cul1 and modulates Cul1 stability in Drosophila}

The genetic evidence described above suggested that Nedd 8 could be directly required for $\mathrm{Ci}^{\mathrm{FL}}$ proteolytic processing, consistent with the hypothesis that neddylation affects $\mathrm{Ci}^{\mathrm{FL}}$ proteolysis through regulating $\mathrm{SCF}^{\text {Slimb }}$ activity. Cullin proteins are the identified targets for Nedd 8 modification. In the Drosophila genome, six Cullin proteins are identified, each corresponding to a mammalian homolog (Fig. 6I, below). Among them, Cull is involved in the formation of SCF complexes that function as E3 ligase. We generated a null Cul1 allele, Cul1 ${ }^{E X}$ (see Materials and Methods). In Cul1 ${ }^{E X}$ homozygous larvae in the first instar stage, the Cull signal detected by $\alpha$ Cull antibodies was almost gone (Fig. 4A, right lane). The residual Cull protein in $\mathrm{Cul1}^{E X}$ larvae was probably maternally contributed.

We further investigated whether Nedd8 conjugates to Cull in Drosophila. Cell extracts of eye-antennal discs and brain lobes isolated from wild-type third instar lar- 


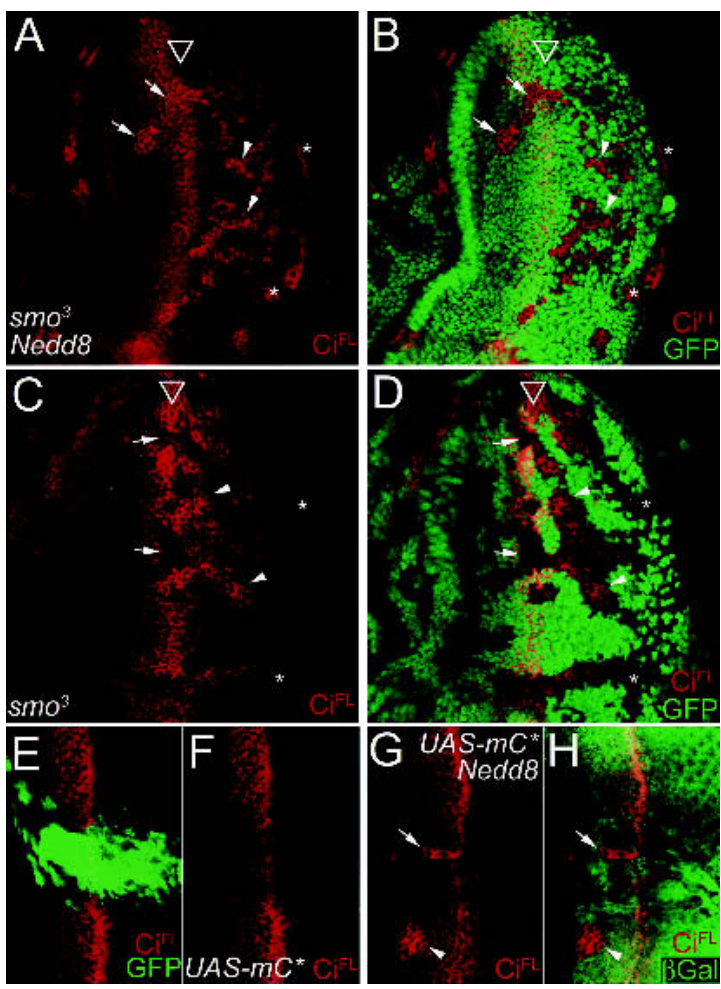

Figure 3. The Nedd8 pathway on $\mathrm{Ci}^{\mathrm{FL}}$ proteolytic processing is downstream of the Hh receptor Smo and PKA activity. $(A-D)$ $\mathrm{Ci}^{\mathrm{FL}}$ accumulation in Nedd8 mutant cells is independent of smo activity. $(A, B)$ A late third-instar eye disc carrying smo and Nedd 8 double mutant clones and stained for $\mathrm{Ci}^{\mathrm{FL}}$ in red. $\mathrm{Ci}^{\mathrm{FL}}$ accumulates in all double mutant clones (marked by the lack of GFP staining in $B$ ) regardless of their locations in the eye disc. $(C, D)$ A late third-instar eye disc carrying smo clones and stained for $\mathrm{Ci}^{\mathrm{FL}}$ in red. In the smo mutant cells marked by the lack of GFP expression (green in $D$ ), $\mathrm{Ci}^{\mathrm{FL}}$ expression is missing in clones anterior to and in the MF (arrows). However, $\mathrm{Ci}^{\mathrm{FL}}$ accumulation is detected in mutant cells in the posterior clones (arrowheads) except near the posterior margin (asterisks). (E-H) Nedd8 is required for PKA activity in promoting $\mathrm{Ci}^{\mathrm{FL}}$ proteolytic processing. $(E, F)$ A late third-instar eye disc expressing PKA catalytic domain $\left(U A S-m C^{\star}\right)$ driven by eq-GAL4 in the equator region, as visualized by the coexpressed GFP (green in $E$ ). Constitutive activation of PKA suppresses $\mathrm{Ci}^{\mathrm{FL}}$ accumulation in MF (red in $F) .(G, H)$ A late third-instar eye disc expressing $U A S-m C^{\star}$ under the control of eq-GAL4 and containing Nedd8 mutant clones. $\mathrm{Ci}^{\mathrm{FL}}$ accumulation (red) persists in the Nedd8 mutant clones even when PKA is constitutively activated in the mutant cells (arrows). The accumulated $\mathrm{Ci}^{\mathrm{FL}}$ level is similar to that in the mutant cells without $\mathrm{mC}^{\star}$ expression (arrowheads). The Nedd8 mutant clones are marked by the lack of arm-lacZ expression (green in $H$ ), and the effect of misexpressed PKA catalytic subunit can be observed by the downregulated $\mathrm{Ci}^{\mathrm{FL}}$ level in $\mathrm{MF}$ cells near the Nedd8 clone.

vae were immunoprecipitated by $\alpha \mathrm{Cull}$ antibodies and immunoblotted by $\alpha$ Nedd 8 antibodies (Fig. 4B, middle lane). The Nedd8-positive signal, indicated by the arrow in Figure 4B, suggests that Cul1 was modified by Nedd8 in Drosophila. Consistently, the Nedd8-modified Cul1 signal disappeared in cell extracts prepared from the first instar Nedd8 mutant larvae (Fig. 4C, arrow).
In addition, we found that unmodified Cull accumulated in the Nedd8 hypomorphic mutants Nedd8 EP(2)2063/ANO15 (Fig. 4D). This effect of Cull accumulation was also observed in Nedd8 null mutant clones in third-instar eye discs (Fig. 4E,F). These data suggested that Nedd 8 modification of Cull might modulate Cull stability.

\section{Cul1 functions in the same pathway as Nedd8 in modulating protein stability}

To test whether Nedd 8 activity in controlling protein stability is mediated through Cull, we examined whether depleting Cull would exhibit the same pheno-
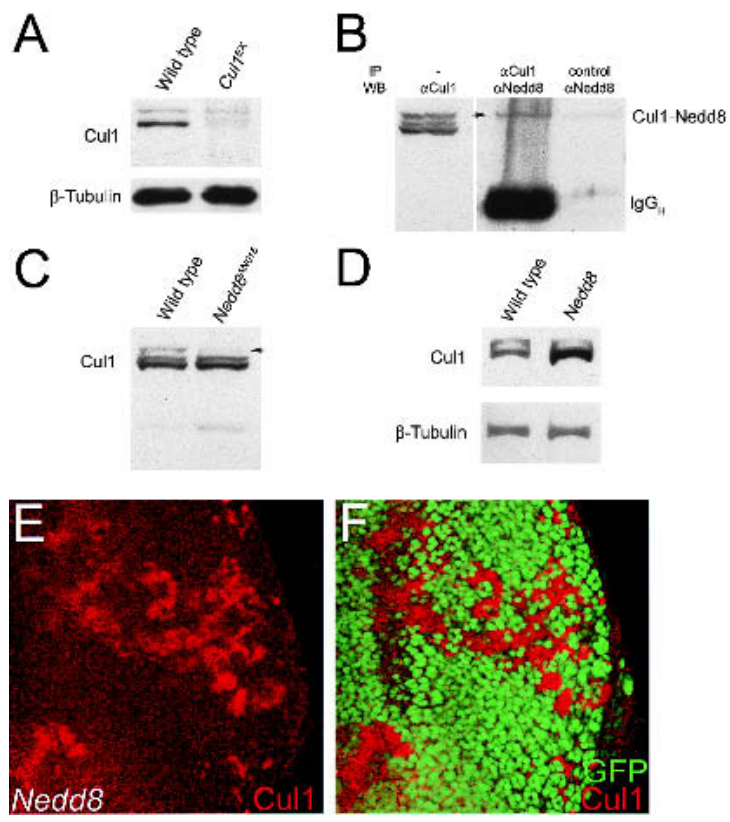

Figure 4. Nedd8 modifies Cull and controls its stability. (A) Western blot by $\alpha \mathrm{Cull}$ antibodies. Cell extracts were prepared from first-instar larvae of wild-type (left lane) and Cu11 ${ }^{E X} \mathrm{mu}-$ tant (right lane). The levels of Cull proteins of $90 \mathrm{kD}$ are greatly reduced in $C u 11^{E X}$ cell extract. $(B)$ Conjugation of Nedd8 to Cull. Western blot of cell extract prepared from the eye discs and brain lobes of third-instar larvae by $\alpha \mathrm{Cull}$ antibodies (left lane). Immunocomplex of Cull from precipitation by $\alpha \mathrm{Cull}$ antibodies is blotted by $\alpha$ Nedd 8 antibodies (middle lane). An arrow indicates the putative Nedd8-modified Cull form. In the control experiment without the addition of $\alpha \mathrm{Cull}$ antibodies in precipitation, no Nedd8 positive signal can be detected (right lane). (C) Immunoblotting of cell extract prepared from firstinstar larvae of wild-type (left lane) and Nedd8 ${ }^{A N O 15}$ (right lane) by $\alpha$ Cull antibodies. The Nedd8-modified form of Cull is missing in Nedd8 larvae (right lane, arrow). (D) In the absence of Nedd8 modification, the Cull level is increased. Western blot analysis of cell extract from third-instar eye discs and brain lobes by $\alpha$ Cull antibodies indicates that the Cull protein is accumulated in $N e d d 8^{A N 015} / N e d d 8^{E P(2) 2063}$ (right lane). (E,F) A late third-instar eye disc containing Nedd8 mutant clones and stained with $\alpha$ Cull antibodies (red). Cull accumulates in the Nedd8 mutant clones (red in $E$ ) that are marked by the lack of GFP expression (green in $F$ ). 
types as depleting Nedd8. Cul1 ${ }^{E X}$ clones were generated in developing wing discs, and the protein levels of $\mathrm{Ci}^{\mathrm{FL}}$ and Arm were examined. Accumulations of $\mathrm{Ci}^{\mathrm{FL}}$ and Arm were found in $\mathrm{Cul1}^{E X}$ mutant cells (Fig. 5A-C and D-F, respectively), identical to the phenotypes observed in Nedd8 mutant clones. In the eye disc, CycE accumulated in Cul1 mutant cells (Fig. 5 G-I). These results suggest that Nedd8 and Cull function together for controlling the protein stability of $\mathrm{Ci}$ and Arm in the wing disc and CycE in the eye disc.

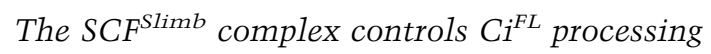
exclusively in cells anterior to the MF of the eye disc

We then tested whether the Cull-based SCF complex is involved in controlling $\mathrm{Ci}^{\mathrm{FL}}$ stability in the eye disc. When located anterior to the MF, Cul1 ${ }^{E X}$ cells accumulated high levels of $\mathrm{Ci}^{\mathrm{FL}}$ (Fig. 6A,B), a phenotype similar to Nedd8 mutant cells. However, Cul1 ${ }^{E X}$ cells that located posterior to the MF only expressed a basal level of $\mathrm{Ci}^{\mathrm{FL}}$, suggesting that the Cull-based SCF complex may not control Ci stability in the posterior cells.

In addition to the Nedd8-Cull core component, the SCF complex also includes a substrate-specific F-box protein. To investigate whether SCF activity in $\mathrm{Ci}^{\mathrm{FL}}$ processing is limited to the anterior cells of the eye disc, we examined the mutant phenotype of slimb that is re-
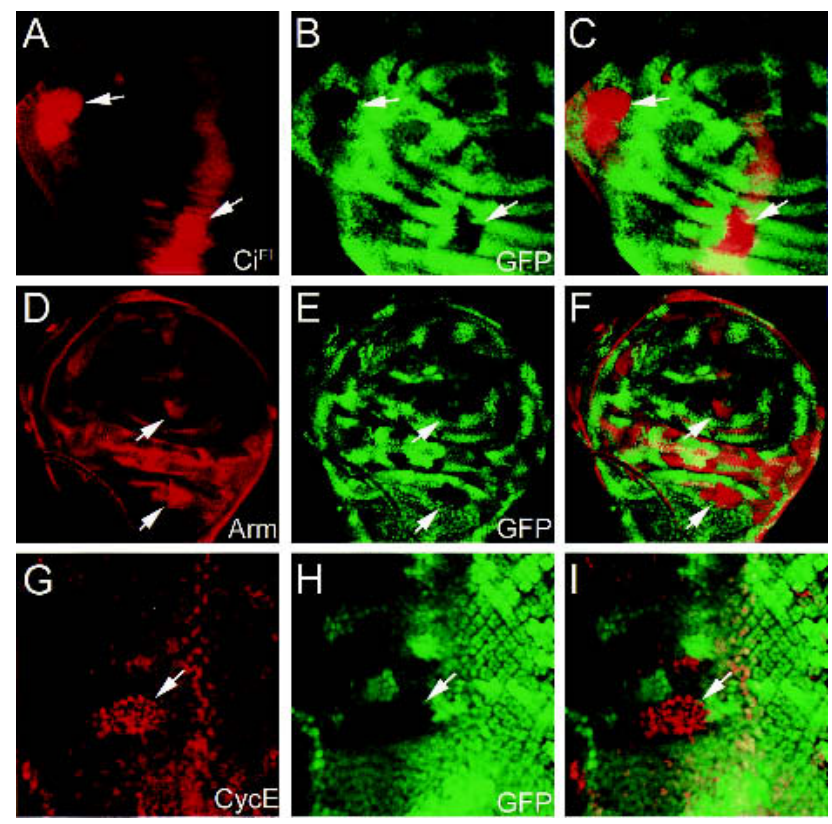

Figure 5. Accumulation of $\mathrm{Ci}^{\mathrm{FL}}, \mathrm{Arm}$, and $\mathrm{CycE}$ in Cul1 mutant cells. Cu11 ${ }^{E X}$ mutant clones are marked by the lack of GFP expression in wing discs (green in $B, E$ ) and eye disc (green in $H$ ). $(A-C) \mathrm{Ci}^{\mathrm{FL}}$ (red in $\left.A, C\right)$ accumulates in the Cul1 ${ }^{E X}$ mutant clones (indicated by arrows) in the anterior compartment of the wing discs. $(D-F)$ In $C u 11^{E X}$ mutant cells, Arm is upregulated (red in $D, F)$ in cytosol (arrows) of wing disc cells. $(G-I)$ Enhancement of CycE protein level (red in $G, I)$ is observed in $C u 11^{E X}$ mutant clones (arrows) in the eye disc. quired for $\mathrm{Ci}^{\mathrm{FL}}$ proteolytic processing in tissues such as wing and leg discs (Jiang and Struhl 1998). When slimb ${ }^{1}$ mutant clones were generated in eye discs, high levels of $\mathrm{Ci}^{\mathrm{FL}}$ accumulation were detected exclusively in clones located anterior to the MF. No accumulation of $\mathrm{Ci}^{\mathrm{FL}}$ could be detected in posterior slimb $b^{1}$ clones (Fig. 6C,D). Suppression of $\mathrm{Ci}^{\mathrm{FL}}$ accumulation in the posterior cells was not due to possible residual activity present in hypomorphic $\operatorname{sim} b^{1}$, because we observed identical results of $\mathrm{Ci}^{\mathrm{FL}}$ accumulation in the strong hypomorphic allele $\operatorname{slimb}^{2}$ and the null allele $\operatorname{sim} b^{P}$ (data not shown).

In summary, our results strongly suggested that in vivo, the Nedd8-modified, Cul1-based SCF ${ }^{\text {Slimb }}$ complex controls $\mathrm{Ci}^{\mathrm{FL}}$ proteolysis in anterior cells. Following the sweep of the MF, $\mathrm{Ci}^{\mathrm{FL}}$ stability in the posterior cells is controlled by an $\mathrm{SCF}^{\text {Slimb }}$-independent mechanism.

Ci downregulation in the posterior cells of the eye disc requires Smo signaling and Nedd8 modification activity

The finding that $\mathrm{Ci}^{\mathrm{FL}}$ accumulated in posterior $s m o^{3}$ clones (Fig. 3C,D, arrowheads; Dominguez 1999) indicated that Smo signaling contributes to the downregulation of $\mathrm{Ci}^{\mathrm{FL}}$ in the posterior cells of the eye disc. This effect is in contrast to the smo role in the MF, where smo is required for $\mathrm{Ci}^{\mathrm{FL}}$ activation (Fig. $3 \mathrm{C}, \mathrm{D}$, arrows). $\mathrm{Ci}^{\mathrm{FL}}$ accumulation was also observed in the posterior Nedd8 mutant clones located proximally to the MF (Fig. 2A,B, arrowheads). In the $s m o^{3}$ Nedd8 double mutant clones, the level of $\mathrm{Ci}^{\mathrm{FL}}$ was further enhanced (Fig. 3A,B, arrowheads), even in clones located distally to the MF (Fig. $3 \mathrm{~A}, \mathrm{~B}$, asterisks), whereas no $\mathrm{Ci}^{\mathrm{FL}}$ accumulation was detected in Nedd8 (Fig. 2A,B, asterisks) or $s m o^{3}$ clones (Fig. $3 \mathrm{C}, \mathrm{D}$, asterisks), suggesting that Nedd 8 and Smo function partially redundantly to downregulate $\mathrm{Ci}$ stability in the posterior cells of the eye disc.

\section{$C i^{F L}$ degradation in the posterior cells of the eye disc is mediated by a Cul3-dependent mechanism}

The involvement of Nedd8 in controlling $\mathrm{Ci}^{\mathrm{FL}}$ levels in the posterior cells of the eye disc suggests that Cullin proteins other than Cull may be involved in the posterior mechanism to control Ci stability. Among the mammalian Cullin family, Cul3 shares with the Cul1-based SCF complex the substrate CycE (Singer et al. 1999). To test whether $\mathrm{Cul} 3$ affects $\mathrm{Ci}^{\mathrm{FL}}$ degradation in the eye disc, we analyzed the available Drosophila Cul3 mutants (see Materials and Methods). We found that $\mathrm{Ci}^{\mathrm{FL}}$ accumulated in Cul3 mutant clones located posterior to the MF (Fig. 6E,F), with a higher level in nondifferentiating cells that surround differentiating photoreceptor clusters. In contrast, no $\mathrm{Ci}^{\mathrm{FL}}$ accumulation was detected in anterior Cul3 mutant clones, indicating that Cul3 controls $\mathrm{Ci}^{\mathrm{FL}}$ protein stability only in the posterior cells of the eye disc. Ci accumulation in posterior Cul3 mutant cells was controlled at the posttranscriptional level because ci expression was normal, as revealed by in situ 

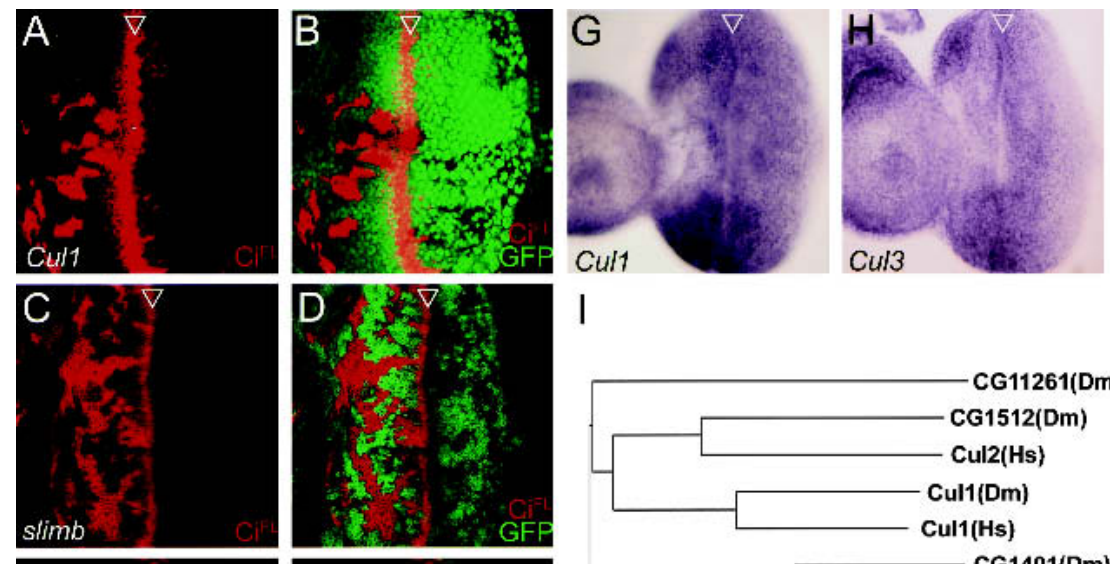

I

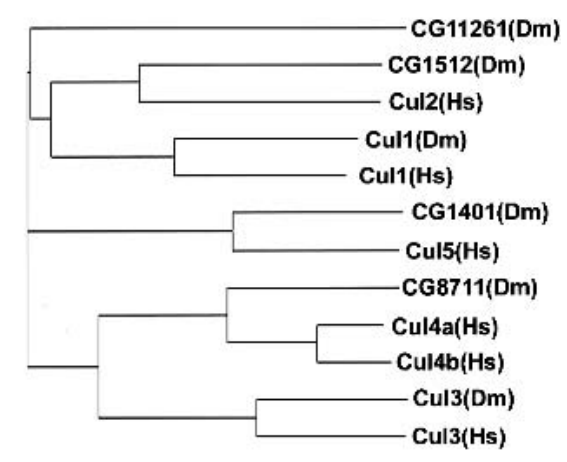

Figure 6. $\mathrm{SCF}^{\mathrm{Slimb}}$ complex and a Cul3based degradation machinery to control the $\mathrm{Ci}^{\mathrm{FL}}$ stability in the anterior and posterior cells of the eye discs, respectively. $(A-D)$ The Cull-based, SCF ${ }^{\text {Slimb }}$ complex functions in the anterior cells to promote $\mathrm{Ci}^{\mathrm{FL}}$ proteolytic processing. In the $\mathrm{Cu}_{11}{ }^{\mathrm{EX}}$ $(A)$ and $\operatorname{slimb}^{1}(C)$ mutant clones located anterior to the $\mathrm{MF}, \mathrm{Ci}^{\mathrm{FL}}$ accumulation is detected (red), whereas in the posterior clones, no accumulation can be observed. The mutant clones of $\operatorname{Cul1}^{E X}(B)$ and $\operatorname{slimb}^{1}(D)$ are marked by the lack of GFP expression. $(E, F)$ In the $\mathrm{Cul}^{g f t 2}$ mutant clones, marked by the lack of GFP expression (green), only posterior clones accumulate $\mathrm{Ci}^{\mathrm{FL}}$ (red). $(G, H)$ The ubiquitous expression patterns of $\mathrm{Cul1}(G)$ and $\mathrm{Cul3}(\mathrm{H})$ in the eye discs as revealed by in situ hybridization with antisense probes of Cul1 and $\mathrm{Cul} 3$, respectively. In the control experiments, the sense probes gave no signals (data not shown). (I) The phylogenetic tree of the Drosophila Cullin family (denoted by Dm) to their human counterparts (Hs). hybridization (data not shown). These results showed that the $\mathrm{Ci}^{\mathrm{FL}}$ degradation machinery in the posterior cells of the eye disc requires a Cul-3-mediated degradation mechanism. $\mathrm{Ci}$ accumulation was also detected in Cul3 mutant cells located in the A/P boundary of the wing disc (data not shown). The level of Arm in Cul3 mutant clones in wing discs and the level of CycE in Cul3 mutant clones in eye discs remained constant /data not shown), suggesting that $\mathrm{Cul3}$ activity was specific to $\mathrm{Ci}$.

In contrast to the Cul1-based $\mathrm{SCF}^{\text {Slimb }}$ complex that controls $\mathrm{Ci}^{\mathrm{FL}}$ processing only in the anterior cells of the eye disc, the Cul3-mediated Ci degradation mechanism is specific to the posterior cells. These specific activities in controlling $\mathrm{Ci}$ protein stability were not caused by differential gene expression of Cul1 and Cul3 in the eye disc. We detected ubiquitous mRNA expression patterns of both Cul1 (Fig. 6G) and Cul3 (Fig. 6H), and ubiquitous Cull protein expression all along the eye disc (Fig. 4E), suggesting that control of specificity is mediated by mechanisms other than regulation of Cul1 and Cul3 expression.

\section{$\mathrm{Ci}^{F L}$ degradation in the posterior cells of the eye disc is constitutive and PKA-independent}

PKA phosphorylation promotes $\mathrm{Ci}^{\mathrm{FL}}$ processing, and plays a role in the Hh signaling pathway for $\mathrm{Ci}$ activation. We therefore examined the requirement of PKA in $\mathrm{Ci}^{\mathrm{FL}}$ degradation in the posterior cells of the eye disc. We generated PKA-deficient cells by overexpressing the regulatory subunit of PKA $\left(U A S-R^{\star}\right)$ that functions to sequester the catalytic subunit and, therefore, to inhibit PKA activity (Li et al. 1995). The UAS- $R^{\star}$ transgene was expressed in random clones of cells labeled with GFP (see Materials and Methods). Consistent with the requirement of PKA activity in $\mathrm{Ci}^{\mathrm{FL}}$ processing, $\mathrm{Ci}^{\mathrm{FL}}$ accumulated when PKA activity was inhibited in GFPpositive cells located anterior to the MF (Fig. 7A,B, arrows). In contrast, no $\mathrm{Ci}^{\mathrm{FL}}$ accumulation could be detected in GFP-positive cells located posterior to the MF (Fig. 7A,B, arrowheads), indicating that $\mathrm{Ci}^{\mathrm{FL}}$ downregulation is not regulated by $\mathrm{PKA}$ activity.

PKA-independent $\mathrm{Ci}^{\mathrm{FL}}$ downregulation in posterior cells of the eye disc could cause either proteolytic processing of $\mathrm{Ci}^{\mathrm{FL}}$ to the short form, $\mathrm{Ci75}$, or complete $\mathrm{Ci}$ degradation. To address this question, we expressed the $U A S-H A C i^{-3 P}$ transgene in which an HA tag was fused to the $\mathrm{N}$ terminus of $\mathrm{Ci}$ and the three PKA phosphorylation sites required for $\mathrm{Ci}$ processing were mutated (Wang et al. 1999). Expression of the phosphorylationdefective form of $\mathrm{Ci}^{\mathrm{FL}}$ was driven by eq-GAL4 in the equator region of the eye disc and monitored by the coexpressed GFP (Fig. 7C). While the $\alpha \mathrm{Ci}^{\mathrm{FL}}$ antibody detected a high level of $\mathrm{Ci}^{\mathrm{FL}}$ in the anterior equator of the eye disc where PKA phosphorylation is required for $\mathrm{Ci}^{\mathrm{FL}}$ processing, expression of $\mathrm{Ci}^{\mathrm{FL}}$ was completely diminished in the posterior cells in which the GFP signal was strongly detected (Fig. 7D). The $\alpha \mathrm{HA}$ antibody that could recognize the full-length $\mathrm{Ci}$ (Ci155) and the short form of $\mathrm{Ci}(\mathrm{Ci75})$ also failed to detect any signal in the posterior region (Fig. 7E), suggesting that instead of processing to $\mathrm{Ci} 75, \mathrm{Ci}^{\mathrm{FL}}$ was completely degraded. We also tested another Ci mutant in which, in addition to the phosphorylation sites, the proteolytic processing site of Ci was also mutated (Wang et al. 1999). Expression of the uncleavable and unphosphorylated $\mathrm{Ci}^{\mathrm{FL}}\left(U A S-H A C i^{U-3 P}\right)$ by eq$G A L 4$ in the equator region revealed no detectable $\mathrm{Ci}$ 
Ou et al.
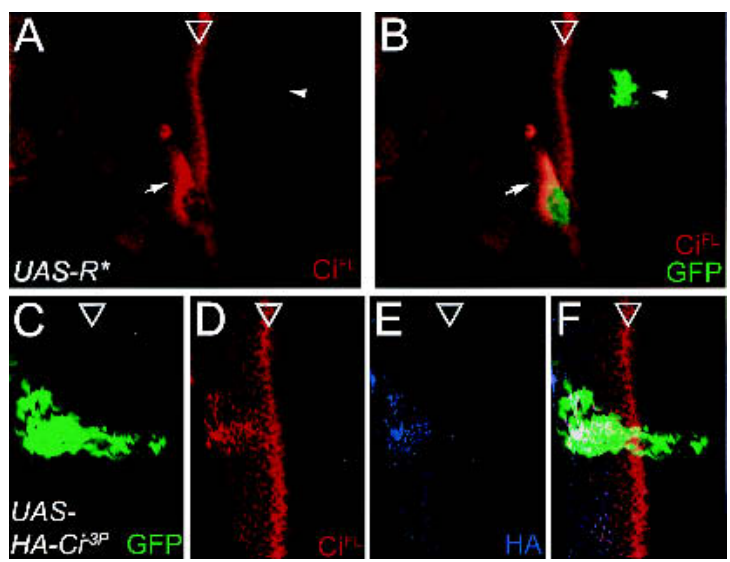

Figure 7. Regulation of $\mathrm{Ci}^{\mathrm{FL}}$ degradation in posterior cells of the eye disc. $(A, B)$ PKA activity is not required for $\mathrm{Ci}^{\mathrm{FL}}$ degradation in the posterior cells. To inhibit PKA activity, the dominant negative form of PKA regulatory domain is expressed in random clones marked by GFP expression (see Materials and Methods). The protein level of $\mathrm{Ci}^{\mathrm{FL}}(\mathrm{red})$ is upregulated in anterior (arrow) but not posterior clones (arrowhead). $(C-F) \mathrm{Ci}^{\mathrm{FL}}$ degradation is independent of PKA phosphorylation. The PKA phosphorylation site-mutated form of $\mathrm{Ci}, \mathrm{Ci}^{-3 \mathrm{P}}$, is expressed by eq-GAL4 in the equator, as shown by the coexpressed GFP $(C)$. (D) Misexpressed $\mathrm{Ci}^{-3 \mathrm{P}}$ is refractory to PKA-mediated proteolytic processing in the anterior cells, as shown by antibody staining for $\mathrm{Ci}^{\mathrm{FL}}$. However, no $\mathrm{Ci}^{-3 \mathrm{P}}$ expression can be detected in the posterior cells. (E) The $\mathrm{Ci}^{-3 \mathrm{P}}$ is fused with an HA tag in the $\mathrm{N}$ terminus, and no signal can be detected with an antibody against HA in the posterior cells, suggesting that both the fulllength and the short form of $\mathrm{Ci}$ are degraded completely. $(F)$ The merged image of $C, D, E$.

level in the posterior equator region (data not shown), similar to the result obtained from expression of UAS$H A C i^{-3 P}$. This result suggested that proteolytic processing of $\mathrm{Ci}^{\mathrm{FL}}$ to the short form Ci75 is not a prerequisite for complete degradation in the posterior cells, in contrast to the proteolytic processing of the phosphorylated $\mathrm{Ci}^{\mathrm{FL}}$ to the short form Ci75 in the anterior cells. To sum up, our results suggested that in the posterior cells of the eye disc, $\mathrm{Ci}^{\mathrm{FL}}$ is degraded constitutively, and this degradation process is independent of PKA phosphorylation.

\section{Discussion}

\section{Nedd8-modified Cul1 is required for the function of different SCF complexes in vivo}

In this work, we first isolated and characterized Drosophila Nedd8 and Cul1 mutants. Immunostaining of the developing discs showed that Nedd8 and Cul1 are required for controlling the protein stabilities of Arm, $\mathrm{Ci}^{\mathrm{FL}}$, and $\mathrm{CycE}$ (Figs. 1,5). In Nedd8 mutant clones, the presence of Cull, although at a higher level (Fig. 4E), is unable to downregulate the protein stability. In addition, we showed that in Drosophila Nedd8 modifies Cull in biochemical assays (Fig. 4B,C). These results indicate that neddylation of Cull is essential for Cull activity in vivo.
Accumulation of Arm and $\mathrm{Ci}^{\mathrm{FL}}$ has also been reported for slimb mutants (Jiang and Struhl 1998). The identified F-box protein Ago has been shown to control CycE degradation in vivo (Moberg et al. 2001). These results are consistent with the idea that individual SCF targets specific substrates for protein degradation via a recognition process mediated by a specific F-box protein, such as Slimb for Arm and Ci, and Ago for CycE in flies. Since Nedd8 affects substrate stability that depends on either Slimb or Ago, we infer that Nedd8 modification regulates SCF activity, but not substrate specificity.

\section{Nedd8 modification regulates both activity and stability of Cul1}

We found that in biochemical assay, the unmodified Cull accumulated with the reduction of Nedd8 activity (Fig. 4D). In Nedd8 mutant cells in the developing eye disc, Cull also accumulated to a high level (Fig. 4E,F), raising the possibility that neddylation activates Cull and at the same time turns the modified Cull into a labile state for protein degradation. In this way, Cull activity could be tightly controlled in signaling pathways during developmental processes. Although the mechanism by which Nedd8-modified Cull is targeted for protein degradation is not clear, it has been shown that some unknown proteins with Nedd8 conjugation are targeted for proteasome degradation by the Nedd8interacting protein NUB1 (Kamitani et al. 2001).

\section{Possible roles of Nedd8 modification and SCF Slimb $^{\text {ind }}$ in Ci proteolytic processing}

In anterior cells of developing discs, we show that $\mathrm{Ci}^{\mathrm{FL}}$ proteolytic processing requires the activity of the Nedd8modified, Cull-based SCF ${ }^{\text {Slimb }}$ complex. This $\mathrm{Ci}^{\mathrm{FL}}$ proteolytic processing is inhibited by Smo signaling and promoted by PKA phosphorylation on $\mathrm{Ci}^{\mathrm{FL}}$. The mechanism by which $\mathrm{Ci}^{\mathrm{FL}}$ is proteolyzed from $\mathrm{Ci}^{\mathrm{FL}}$ to $\mathrm{Ci} 75$ is not clear. We propose that Nedd8 modifies and activates $\mathrm{SCF}^{\text {Slimb }}$ for Ci ubiquitination and then proteolysis, because of Cull modification by Nedd 8 and $\mathrm{Ci}^{\mathrm{FL}}$ accumulation in Nedd8, Cul1, and slimb mutants. Consistently, proteolysis of $\mathrm{Ci}^{\mathrm{FL}}$ depends on $26 \mathrm{~S}$ proteasome activity (Ingham 1998). However, ubiquitinated Ci is not detected in cells treated with $26 \mathrm{~S}$ proteasome inhibitors (Chen et al. 1999). We could not exclude the possibility that Nedd8 directly modifies Ci through the SCF complex, because it has been shown that Nedd8 might direct its conjugates to proteasome-dependent protein degradation through NUB1 (Kamitani et al. 2001). In this case, SCF could function as the E3 ligase for Nedd8 modification on its substrate (Kamura et al. 1999a).

In the Hh signaling pathway, it is not clear how Smo signaling prevents $\mathrm{Ci}^{\mathrm{FL}}$ from proteolysis. According to our double mutant analysis (Fig. 3), Nedd8 could be downstream or parallel to Smo and PKA signaling. Thus, it is possible that $\mathrm{Hh}$ signaling prevents $\mathrm{Ci}^{\mathrm{FL}}$ from proteolysis through downregulating the level of Nedd8- 
modified Cull. However, we failed to detect a change in the level of Nedd8-modified Cull in cell extracts prepared from the eye discs with ectopic Hh expression (data not shown). We infer that $\mathrm{Hh}$ may affect $\mathrm{Ci}^{\mathrm{FL}}$ proteolysis through a Nedd8-independent mechanism.

\section{A distinct protein degradation mechanism in controlling Ci stability in posterior cells of the eye disc}

We propose two modes of Ci downregulation in Drosophila eye development (Fig. 8). In the undifferentiated cells anterior to the MF, Ci is phosphorylated by PKA constantly and processed by an $\mathrm{SCF}^{\text {Slimb }}$-dependent mechanism to generate the repressor form of Ci75. Upon binding to $\mathrm{Hh}$, cells in the MF transduce Smo signaling to prevent this proteolytic processing. Thus, the transcriptional activator $\mathrm{Ci}^{\mathrm{FL}}$ is preserved for activation of downstream genes in the MF.

In the posterior cells that are undergoing differentiation, a novel mechanism controls Ci degradation. Our mutant analyses suggest that this mechanism is comprised of Smo signaling, Nedd8 modification, and Cul3 activity. The effect of Smo signaling in promoting $\mathrm{Ci}$ degradation in the posterior cells is in contrast to its effect on the anterior cells, in which Smo signaling prohibits $\mathrm{Ci}^{\mathrm{FL}}$ processing. In addition to Smo signaling, Nedd8 modification activity also participates in this posterior Ci degradation. Further Cul1 mutant analysis suggests that Cullin proteins other than Cull are likely involved in this posterior degradation mechanism. This hypothesis has led to the identification of Cul3 as one candidate functioning in Ci degradation. More surprisingly, Cul3 activity is very restricted; Cul3 controls $\mathrm{Ci}$ degradation in the posterior, but not anterior, cells of the eye disc. $\mathrm{Ci}^{\mathrm{FL}}$ accumulation may have an impact on proper differentiation of the posterior cells. In Cul3 mutants, cone cell differentiation is affected (C.-Y. Ou and C.-T. Chien, unpubl.), probably due to the accumulation of $\mathrm{Ci}^{\mathrm{FL}}$.

Furthermore, the Ci degradation process is also distinct in posterior cells; Ci degradation is independent of PKA phosphorylation and proteolytic processing to the short form Ci-75 (Fig. 7). Based on these results, we propose that Smo signaling, acting in concert with the
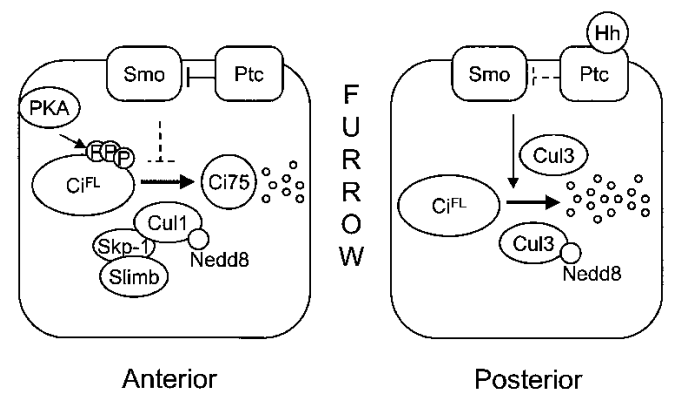

Figure 8. A proposed model for Ci degradation in Drosophila eye development (see Discussion for details).
Nedd8 pathway, activates a Cul3-based ubiquitin ligase to degrade $\mathrm{Ci}$ in a PKA-independent mechanism in posterior cells of the eye disc.

It is not clear how Nedd8 modifies Cul3 in flies. We observed strong genetic interaction between Nedd8 and Cul3 during eye and antennal development (Y.-F. Lin and C.-T. Chien, unpubl.), suggesting that Nedd8 may also regulate Cul3. However, depletion of Nedd8 activity only affects posterior cells abutting the MF (Fig. 2A), in contrast to depletion of Cul3 activity, which increases the $\mathrm{Ci}^{\mathrm{FL}}$ level in all posterior clones (Fig. 6E), indicating that some Cul3 activity is Nedd8-independent. It is possible that a basal Cul3 activity for Ci degradation is further enhanced by Nedd8 modification near the MF in which accumulated Ci may require efficient degradation for cells to enter proper differentiation.

\section{Switch of Ci degradation mechanisms}

Different protein-protein interactions may result in a switch between two Ci degradation mechanisms in eye discs. $\mathrm{Ci}$ is known to interact with $\mathrm{Cos} 2, \mathrm{Fu}$, and $\mathrm{Su}(\mathrm{fu})$ to comprise a protein complex (for review, see Ingham and McMahon 2001) that promotes Ci degradation. Cos2, a motor-like protein with a kinesin motif, is required for tethering $\mathrm{Ci}$ in the cytosolic compartment and Ci proteolytic processing in the Drosophila developing wing. Similarly, $\mathrm{Fu}$, a serine/threonine kinase, is also required for Ci processing. However, in $\mathrm{Su}(\mathrm{fu})$ mutants, levels of both long and short forms of $\mathrm{Ci}$ are reduced (Ohlmeyer and Kalderon 1998; Lefers et al. 2001), suggesting that $\mathrm{Su}(\mathrm{fu})$ plays an additional role in Ci protein stability. Interestingly, the role of $\mathrm{Su}(\mathrm{fu})$ in controlling Ci stability seems modulated by Hh signaling. Our results indicate that, in contrast to the effect of Hh signaling in the anterior cells, Hh signaling downregulates the $\mathrm{Ci}$ level in the posterior cells of the eye disc. It is possible that the Ci protein complex is modulated by the sweep of the MF, and this change requires Hh signaling to expose $\mathrm{Ci}$ to the Cul3-based protein degradation machinery. Alternatively, additional factors may be activated by the sweeping of the MF and be required for Hh signaling to induce Cul3 activity that leads to constitutive Ci degradation.

Similar to $\mathrm{Ci}$, CycE is degraded by two different mechanisms in mammalian cells. The Cull-based SCF complex recognizes the phosphorylated form of Cdk2bound CycE for ubiquitination (Dealy et al. 1999; Skowyra et al. 1999; Koepp et al. 2001; Strohmaier et al. 2001; Yeh et al. 2001), and Cul3 targets unbound CycE for ubiquitination, which is independent of protein phosphorylation (Singer et al. 1999). $\beta$-catenin is also degraded by two different mechanisms in mammalian cells (Polakis 2001). One mechanism involves the $\mathrm{SCF}^{\beta} \operatorname{TrCP}$ complex ( $\beta$ TrCP is the mammalian homolog of Slimb) that recognizes phosphorylated $\beta$-catenin. The other mechanism involves the Ebi complex comprised of Ebi, Skp1, SIP, and Siah-1, which targets $\beta$-catenin in a phosphorylation-independent manner. 


\section{Degradation of the Gli proteins in vertebrates}

In vertebrates, the three Ci-related proteins Gli1, Gli2, and Gli3 transduce Hh signaling in different developmental processes (for review, see Ingham and McMahon 2001). Ectopic expression of the Gli proteins in Drosophila showed that Gli2 and Gli3, but not Gli1, are proteolyzed to generate repressor forms. Although the proteolytic cleavage of Gli3 is under the regulation of $\mathrm{Hh}$ signaling, Gli2 proteolysis is independent of $\mathrm{Hh}$ (AzaBlanc et al. 2000). Consistently, proteolytic processing of Gli3, but not Gli1, has been observed in mouse embryos (Dai et al. 1999). In cultured cells, Gli3 processing is dependent on Hh signaling and PKA activity, in contrast to Gli1 and Gli2 (Dai et al. 1999; Ruiz i Altaba 1999). Apparently, the Gli proteins are controlled by different protein downregulation mechanisms. It will be interesting to investigate whether Nedd8, Cul1, Cul3, and perhaps other Cullins are differentially involved in protein degradation of the Gli proteins.

\section{Materials and methods}

\section{Genetics}

The Drosophila Nedd8 alleles, Nedd $8^{A N 015}$ and Nedd8 $8^{A N O 24}$ (Fig. 1A), were recovered in an EMS screen for lethal mutations that failed to complement $D f(2 L) T W 3(36 F 7-9,37 \mathrm{~B} 2-7)$. The insertion site of $E P(2) 2063$ is located $91 \mathrm{bp}$ upstream of the translation start site of Nedd8. Imprecise excision of the EP element generated a null allele Nedd $8^{172}$ that included a deletion of the N-terminal half of the Nedd8 protein (aa 1-45), and a weak allele $N e d d 8^{203}$ that included a small insertion of $45 \mathrm{bp}$ in the EP insertion site.

The Drosophila lin-19 allele (from Bloomington Stock Center) contains a P-element insertion in the first exon, $990 \mathrm{bp}$ upstream of the start ATG codon. lin-19 homozygotes died in the third-instar larval stage. Excision of the P-element rescued the larval lethality, suggesting that the P-element insertion caused the lethality. Immunoblotting lin-19 cell extracts for Cull, and complementation test with a Cul1 null allele, Cul1 ${ }^{E X}$, suggested that $l i n-19$ is a hypomorphic allele of Cul1. We performed imprecise excision of the P-element to isolate a null allele Cu11 ${ }^{E X}$, which includes a deletion of aa 1-90 of the Cull protein. When homozygous, or in trans to the deficiency $D f(2 R) C A 53$ (43E7-18;44B6) that uncovers Cul1, Cul1 ${ }^{E X}$ caused lethality in the second-instar larval stage, suggesting that $\mathrm{Cul1}^{E X}$ is a null allele. Cu13 ${ }^{06430}$ is a P-element insertion line, and $\mathrm{Cu}_{1} \mathrm{~g}^{\mathrm{ft} 2}$ is an EMS allele (both from Bloomington Stock Center), and both function like genetic null and exhibit identical phenotypes described. To identify homozygotes of Nedd8, $\mathrm{Cul1}$, or $\mathrm{Cul3}$, the green balancer CyO Kr-GAL4 UAS-GFP was used.

Other fly stocks used were $f^{36 a}, M(2 L) 24 F f^{+30 b}$ (Cifuentes and Garcia-Bellido 1997), ey-FLP, cl2L3 (Newsome et al. 2000), ubinlsGFP (gift from S. Luschnig), arm-LacZ FRT ${ }^{40 A}$ (gift from J. Treisman), ci-LacZ (Eaton and Kornberg 1990), dpp-LacZ (Blackman et al. 1991), smo (Chen and Struhl 1996; van den Heuvel and Ingham 1996), Act $<y+<$ Gal4 UAS-GFP ${ }^{S 65 T}$ (Ito et al. 1997), eq-GAL4 (gift from H. Sun), UAS- $m C^{\star}, U A S-R^{\star}$ (Li et al. 1995), UAS-HACi ${ }^{-3 P}$ (Wang et al. 1999), slimb ${ }^{1}$, slimb ${ }^{2}$, and slimb ${ }^{P 1493}$ (Jiang and Struhl 1998). The following flies were used to generate Nedd8 clones: hs-FLP ${ }^{122}$; Nedd $8^{A N O 15} F R T^{40 A} /$ cl2L3 P[ubi-nlsGFP] FRT ${ }^{40 A}$ (Fig. 1G-L), W ey-FLP; Nedd8 ${ }^{A N O 15}$
FRT $^{40 A} /$ cl2L3 P[arm-LacZ] FRT ${ }^{40 A}$ (Figs. 1M-O, 2H), and w eyFLP; Nedd8 ${ }^{A N O 15}$ FRT $^{40 A} /$ cl2L3 P[ubi-nlsGFP] FRT ${ }^{40 A}$ (Figs. $2 \mathrm{~A}-\mathrm{G}$ and $4 \mathrm{E}, \mathrm{F})$. We used $w$ ey-FLP; $s \mathrm{mo}^{3} \mathrm{FRT}^{40 A} / \mathrm{cl} 2 \mathrm{~L} 3 \mathrm{P}[\mathrm{ubi}-$ $n 1 s G F P] F R T^{40 A}$ flies for generation of smo clones, and $W$ eyFLP; SMO $^{3}$ Nedd $8^{A N O 15}$ FRT ${ }^{40 A} /$ cl2L3 P[ubi-nlsGFP] FRT ${ }^{40 A}$ for Nedd8 and smo double mutant clones. To generate Nedd8 clones in $\mathrm{mC}^{\star}$ expression domain in eye discs, UAS- $m C^{*}$ Nedd8 ${ }^{A N O 15}$ FRT ${ }^{40 A} /$ cl2L3 P[ubi-nlsGFP] FRT ${ }^{40}$; eq-Gal4 UASGFP UAS-Flp flies were used. To generate clones expressing $\mathrm{R}^{*}$, hs-Flp, Act<y+<Gal4 UAS-GFP ${ }^{S 65 T} / U A S-R^{\star}$ flies were used. To generate Cul1 and Cul3 clones, we used w ey-FLP (or hs-FLP); $F_{R T}^{42} C^{4 u 11^{E X}} / F R T^{42} P[u b i-n l s G F P]$ and $w$ ey-FLP;Cul3 ${ }^{\text {ftt } 2}$ $F R T^{40 A} /$ cl2L3 P[ubi-nlsGFP] FRT ${ }^{40 A}$ flies, respectively.

\section{Immunohistochemistry, Western blotting,} and immunoprecipitation

The imaginal discs were fixed and stained as described previously (Chen and Chien 1999). The primary antibodies used were rat $\alpha \mathrm{Ci}(1: 1$; Motzny and Holmgren 1995), rabbit $\alpha$ Ato $(1: 1000$, Jarman et al. 1994), rabbit $\alpha \beta$-galactosidase (1:1000; Cappel), rat $\alpha$ Elav (1:125; Developmental Studies Hybridoma Bank), mouse $\alpha$ Arm N27A1 (1:100; Peifer et al. 1994), mouse $\alpha$ CycE (1:3; Moberg et al. 2001), mouse $\alpha \mathrm{HA}$ (1:100; Roche), and rabbit $\alpha$ Myc (9E10, 1:250; Santa Cruz).

The Western blotting and immunoprecipitation were performed as in standard protocol. The primary antibodies used were rabbit $\alpha$ Cul1 (1:250; Zymed) and rabbit $\alpha$ Nedd8 (1:500; Alexis). For immunoprecipitation of Cul1, 200- $\mu \mathrm{L}$ cell extracts from eye imaginal discs and brains of 50 third-instar larvae were added with $5 \mu \mathrm{g}$ of rabbit $\alpha \mathrm{Cull}$ antibodies. In the control experiment, the rabbit $\alpha$ Cull antibodies were not added.

\section{Acknowledgments}

We thank H.Y. Sun, A. Garcíbia-Bellido, B. Dickson, J. Treisman, J. Jiang, R. Holmgren, T. Kornberg, S. Luschnig, H. Richardson, J.-C. Hsu, T.-B. Chou, and the Bloomington Stock Center for fly stocks and reagents. We especially thank J. Jiang for discussions and comments on the manuscript. We are grateful to J.-L. Chao, C.-C. Chang, Y.-C. Tsai, J.-M. Bai, Y.-H. Chou, S.-D. Yeh, R.-Y. Lin, and all lab members for advice and technical support. This work was supported by grants from Academia Sinica and the National Science Council of Taiwan.

The publication costs of this article were defrayed in part by payment of page charges. This article must therefore be hereby marked "advertisement" in accordance with 18 USC section 1734 solely to indicate this fact.

\section{References}

Alcedo, J., Zou, Y., and Noll, M. 2000. Posttranscriptional regulation of Smoothened is part of a self-correcting mechanism in the Hedgehog signaling system. Mol. Cell 6: 457-465.

Aza-Blanc, P., Lin, H.Y., Ruiz i Altaba, A., and Kornberg, T.B. 2000. Expression of the vertebrate Gli proteins in Drosophila reveals a distribution of activator and repressor activities. Development 127: 4293-4301.

Blackman, R.K., Sanicola, M., Raftery, L.A., Gillevet, T., and Gelbart, W.M. 1991. An extensive 3' cis-regulatory region directs the imaginal disk expression of decapentaplegic, a member of the TGF-beta family in Drosophila. Development 111: 657-666.

Chen, C.H., von Kessler, D.P., Park, W., Wang, B., Ma, Y., and Beachy, P.A. 1999. Nuclear trafficking of Cubitus interrup- 
tus in the transcriptional regulation of Hedgehog target gene expression. Cell 98: 305-316.

Chen, C.K. and Chien, C.T. 1999. Negative regulation of atonal in proneural cluster formation of Drosophila R8 photoreceptors. Proc. Natl. Acad. Sci. 96: 5055-5060.

Chen, Y. and Struhl, G. 1996. Dual roles for Patched in sequestering and transducing Hedgehog. Cell 87: 553-563.

Chen, Y., Gallaher, N., Goodman, R.H., and Smolik, S.M. 1998. Protein kinase A directly regulates the activity and proteolysis of cubitus interruptus. Proc. Natl. Acad. Sci. 95: 23492354.

Cifuentes, F.J. and Garcia-Bellido, A. 1997. Proximo-distal specification in the wing disc of Drosophila by the nubbin gene. Proc. Natl. Acad. Sci. 94: 11405-11410.

Dai, P., Akimaru, H., Tanaka, Y., Maekawa, T., Nakafuku, M., and Ishii, S. 1999. Sonic Hedgehog-induced activation of the Gli1 promoter is mediated by GLI3. I. Biol. Chem. 274: 8143-8152.

Dealy, M.J., Nguyen, K.V., Lo, J., Gstaiger, M., Krek, W., Elson, D., Arbeit, J., Kipreos, E.T., and Johnson, R.S. 1999. Loss of Cul1 results in early embryonic lethality and dysregulation of cyclin E. Nat. Genet. 23: 245-248.

Denef, N., Neubuser, D., Perez, L., and Cohen, S.M. 2000. Hedgehog induces opposite changes in turnover and subcellular localization of patched and smoothened. Cell 102: 521531.

Deshaies, R.J. 1999. SCF and Cullin/Ring H2-based ubiquitin ligases. Annu. Rev. Cell Dev. Biol. 15: 435-467.

Dominguez, M. 1999. Dual role for Hedgehog in the regulation of the proneural gene atonal during ommatidia development. Development 126: 2345-2353.

Dominguez, M. and Hafen, E. 1997. Hedgehog directly controls initiation and propagation of retinal differentiation in the Drosophila eye. Genes \& Dev. 11: 3254-3264.

Eaton, S. and Kornberg, T.B. 1990. Repression of ci-D in posterior compartments of Drosophila by engrailed. Genes \& Dev. 4: 1068-1077.

Greenwood, S. and Struhl, G. 1999. Progression of the morphogenetic furrow in the Drosophila eye: The roles of Hedgehog, Decapentaplegic and the Raf pathway. Development 126: 5795-5808.

Heberlein, U., Wolff, T., and Rubin, G.M. 1993. The TGF beta homolog $d p p$ and the segment polarity gene hedgehog are required for propagation of a morphogenetic wave in the Drosophila retina. Cell 75: 913-926.

Hori, T., Osaka, F., Chiba, T., Miyamoto, C., Okabayashi, K., Shimbara, N., Kato, S., and Tanaka, K. 1999. Covalent modification of all members of human cullin family proteins by NEDD8. Oncogene 18: 6829-6834.

Ingham, P.W. 1998. Transducing Hedgehog: The story so far. EMBO J. 17: 3505-3511.

Ingham, P.W. and McMahon, A.P. 2001. Hedgehog signaling in animal development: Paradigms and principles. Genes \& Dev. 15: 3059-3087.

Ingham, P.W., Nystedt, S., Nakano, Y., Brown, W., Stark, D., van den Heuvel, M., and Taylor, A.M. 2000. Patched represses the Hedgehog signalling pathway by promoting modification of the Smoothened protein. Curr. Biol. 10: $1315-1318$.

Ito, K., Awano, W., Suzuki, K., Hiromi, Y., and Yamamoto, D. 1997. The Drosophila mushroom body is a quadruple structure of clonal units each of which contains a virtually identical set of neurones and glial cells. Development 124: 761771.

Jarman, A.P., Grell, E.H., Ackerman, L., Jan, L.Y., and Jan, Y.N. 1994. atonal is the proneural gene for Drosophila photore- ceptors. Nature 369: 398-400.

Jiang, J. and Struhl, G. 1998. Regulation of the Hedgehog and Wingless signalling pathways by the F- box/WD40-repeat protein Slimb. Nature 391: 493-496.

Kamitani, T., Kito, K., Kamitani, T.F., and Yeh, E.T. 2001. Targeting of NEDD8 and its conjugates for proteasomal degradation by NUB1. J. Biol. Chem. 3: 3.

Kamura, T., Conrad, M.N., Yan, Q., Conaway, R.C., and Conaway, J.W. 1999a. The Rbxl subunit of SCF and VHL E3 ubiquitin ligase activates Rubl modification of cullins Cdc53 and Cul2. Genes \& Dev. 13: 2928-2933.

Kamura, T., Koepp, D.M., Conrad, M.N., Skowyra, D., Moreland, R.J., Iliopoulos, O., Lane, W.S., Kaelin Jr., W.G., Elledge, S.J., Conaway, R.C., et al. 1999b. Rbx1, a component of the VHL tumor suppressor complex and SCF ubiquitin ligase. Science 284: 657-661.

Kawakami, T., Chiba, T., Suzuki, T., Iwai, K., Yamanaka, K., Minato, N., Suzuki, H., Shimbara, N., Hidaka, Y., Osaka, F., et al. 2001. NEDD8 recruits E2-ubiquitin to SCF E3 ligase. EMBO J. 20: 4003-4012.

Koepp, D.M., Schaefer, L.K., Ye, X., Keyomarsi, K., Chu, C., Harper, J.W., and Elledge, S.J. 2001. Phosphorylation-dependent ubiquitination of cyclin $\mathrm{E}$ by the $\mathrm{SCF}^{\mathrm{Fbw} 7}$ ubiquitin ligase. Science 294: 173-177.

Lefers, M.A., Wang, Q.T., and Holmgren, R.A. 2001. Genetic dissection of the Drosophila Cubitus interruptus signaling complex. Dev. Biol. 236: 411-420.

Li, W., Ohlmeyer, J.T., Lane, M.E., and Kalderon, D. 1995. Function of protein kinase $\mathrm{A}$ in hedgehog signal transduction and Drosophila imaginal disc development. Cell 80: 553-562.

Ma, C., Zhou, Y., Beachy, P.A., and Moses, K. 1993. The segment polarity gene hedgehog is required for progression of the morphogenetic furrow in the developing Drosophila eye. Cell 75: 927-938.

Maniatis, T. 1999. A ubiquitin ligase complex essential for the NF- $\kappa B$, Wnt/Wingless, and Hedgehog signaling pathways. Genes \& Dev. 13: 505-510.

Moberg, K.H., Bell, D.W., Wahrer, D.C., Haber, D.A., and Hariharan, I.K. 2001. Archipelago regulates Cyclin E levels in Drosophila and is mutated in human cancer cell lines. $\mathrm{Na}$ ture 413: 311-316.

Morimoto, M., Nishida, T., Honda, R., and Yasuda, H. 2000. Modification of cullin-1 by ubiquitin-like protein Nedd8 enhances the activity of SCF ${ }^{\text {skp2 }}$ toward $27^{\text {kip } 1}$. Biochem. Biophys. Res. Commun. 270: 1093-1096.

Motzny, C.K. and Holmgren, R. 1995. The Drosophila cubitus interruptus protein and its role in the wingless and hedgehog signal transduction pathways. Mech. Dev. 52: 137-150.

Newsome, T.P., Asling, B., and Dickson, B.J. 2000. Analysis of Drosophila photoreceptor axon guidance in eye-specific mosaics. Development 127: 851-860.

Ohlmeyer, J.T. and Kalderon, D. 1998. Hedgehog stimulates maturation of Cubitus interruptus into a labile transcriptional activator. Nature 396: 749-753.

Ohta, T., Michel, J.J., Schottelius, A.J., and Xiong, Y. 1999. ROC1, a homolog of APC11, represents a family of cullin partners with an associated ubiquitin ligase activity. Mol. Cell 3: 535-541.

Osaka, F., Kawasaki, H., Aida, N., Saeki, M., Chiba, T., Kawashima, S., Tanaka, K., and Kato, S. 1998. A new NEDD8ligating system for cullin-4A. Genes \& Dev. 12: 2263-2268.

Osaka, F., Saeki, M., Katayama, S., Aida, N., Toh, E.A., Kominami, K., Toda, T., Suzuki, T., Chiba, T., Tanaka, K., et al. 2000. Covalent modifier NEDD8 is essential for SCF ubiquitin-ligase in fission yeast. $E M B O J$. 19: 3475-3484.

Peifer, M., Sweeton, D., Casey, M., and Wieschaus, E. 1994. 
Ou et al.

wingless signal and Zeste-white 3 kinase trigger opposing changes in the intracellular distribution of Armadillo. Development 120: 369-380.

Podust, V.N., Brownell, J.E., Gladysheva, T.B., Luo, R.S., Wang, C., Coggins, M.B., Pierce, J.W., Lightcap, E.S., and Chau, V. 2000. A Nedd8 conjugation pathway is essential for proteolytic targeting of $\mathrm{p} 27^{\mathrm{Kip} 1}$ by ubiquitination. Proc. Natl. Acad. Sci. 97: 4579-4584.

Polakis, P. 2001. More than one way to skin a catenin. Cell 105: $563-566$.

Pozo, J.C., Timpte, C., Tan, S., Callis, J., and Estelle, M. 1998. The ubiquitin-related protein RUB1 and auxin response in Arabidopsis. Science 280: 1760-1763.

Price, M.A. and Kalderon, D. 1999. Proteolysis of Cubitus interruptus in Drosophila requires phosphorylation by protein kinase A. Development 126: 4331-4339.

Read, M.A., Brownell, J.E., Gladysheva, T.B., Hottelet, M., Parent, L.A., Coggins, M.B., Pierce, J.W., Podust, V.N., Luo, R.S., Chau, V., et al. 2000. Nedd8 modification of Cul-1 activates $\mathrm{SCF}^{\beta T r C P}$-dependent ubiquitination of $\mathrm{I}^{\mathrm{B}} \mathrm{B} \alpha$. Mol. Cell. Biol. 20: 2326-2333.

Ready, D.F., Hanson, T.E., and Benzer, S. 1976. Development of the Drosophila retina, a neurocrystalline lattice. Dev. Biol. 53: $217-240$.

Ruiz i Altaba, A. 1999. Gli proteins encode context-dependent positive and negative functions: Implications for development and disease. Development 126: 3205-3216.

Schwechheimer, C., Serino, G., Callis, J., Crosby, W.L., Lyapina, S., Deshaies, R.J., Gray, W.M., Estelle, M., and Deng, X.W. 2001. Interactions of the COP9 signalosome with the E3 ubiquitin ligase $\mathrm{SCF}^{\mathrm{TIR} 1}$ in mediating auxin response. Science 292: 1379-1382.

Seol, J.H., Feldman, R.M., Zachariae, W., Shevchenko, A., Correll, C.C., Lyapina, S., Chi, Y., Galova, M., Claypool, J., Sandmeyer, S., et al. 1999. Cdc53/cullin and the essential Hrt1 RING-H2 subunit of SCF define a ubiquitin ligase module that activates the E2 enzyme Cdc34. Genes \& Dev. 13: $1614-1626$.

Singer, J.D., Gurian-West, M., Clurman, B., and Roberts, J.M. 1999. Cullin-3 targets cyclin E for ubiquitination and controls S phase in mammalian cells. Genes \& Dev. 13: 2375 2387.

Skowyra, D., Koepp, D.M., Kamura, T., Conrad, M.N., Conaway, R.C., Conaway, J.W., Elledge, S.J., and Harper, J.W. 1999. Reconstitution of G1 cyclin ubiquitination with complexes containing $\mathrm{SCF}^{\mathrm{Grr} 1}$ and Rbx1. Science 284: 662-665.

Spencer, E., Jiang, J., and Chen, Z.J. 1999. Signal-induced ubiquitination of I $\mathrm{KB} \alpha$ by the F-box protein Slimb $/ \beta$-TrCP. Genes \& Dev. 13: 284-294.

Strohmaier, H., Spruck, C.H., Kaiser, P., Won, K.A., Sangfelt, O., and Reed, S.I. 2001. Human F-box protein hCdc4 targets cyclin $\mathrm{E}$ for proteolysis and is mutated in a breast cancer cell line. Nature 413: 316-322.

Tateishi, K., Omata, M., Tanaka, K., and Chiba, T. 2001. The NEDD8 system is essential for cell cycle progression and morphogenetic pathway in mice. J. Cell. Biol. 155: 571-579.

van den Heuvel, M. and Ingham, P.W. 1996. smoothened encodes a receptor-like serpentine protein required for hedgehog signalling. Nature 382: 547-551.

Wada, H., Kito, K., Caskey, L.S., Yeh, E.T., and Kamitani, T. 1998. Cleavage of the C-terminus of NEDD8 by UCH-L3. Biochem. Biophys. Res. Commun. 251: 688-692.

Wang, G., Wang, B., and Jiang, J. 1999. Protein kinase A antagonizes Hedgehog signaling by regulating both the activator and repressor forms of Cubitus interruptus. Genes \& Dev. 13: $2828-2837$.
Winston, J.T., Strack, P., Beer-Romero, P., Chu, C.Y., Elledge, S.J., and Harper, J.W. 1999. The SCF ${ }^{\beta-T^{-T C P}}$-ubiquitin ligase complex associates specifically with phosphorylated de-

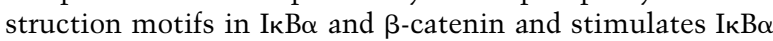
ubiquitination in vitro. Genes \& Dev. 13: 270-283.

Yaron, A., Hatzubai, A., Davis, M., Lavon, I., Amit, S., Manning, A.M., Andersen, J.S., Mann, M., Mercurio, F., and Ben-Neriah, Y. 1998. Identification of the receptor component of the ІкB $\alpha$-ubiquitin ligase. Nature 396: 590-594.

Yeh, E.T., Gong, L., and Kamitani, T. 2000. Ubiquitin-like proteins: New wines in new bottles. Gene 248: 1-14.

Yeh, K.H., Kondo, T., Zheng, J., Tsvetkov, L.M., Blair, J., and Zhang, H. 2001. The F-box protein SKP2 binds to the phosphorylated threonine 380 in cyclin $\mathrm{E}$ and regulates ubiquitindependent degradation of cyclin E. Biochem. Biophys. Res. Commun. 281: 884-890. 


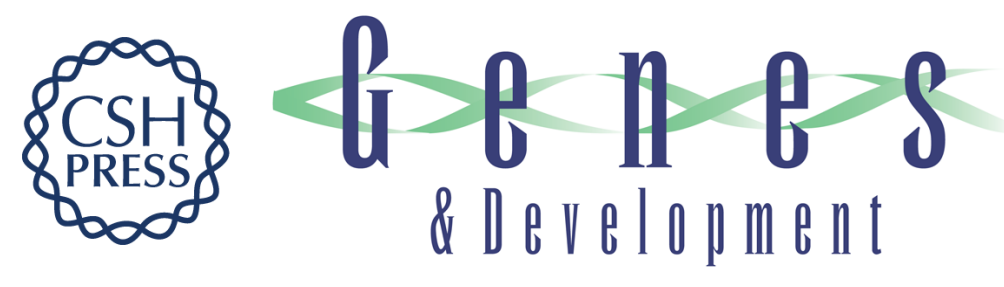

\section{Distinct protein degradation mechanisms mediated by Cul1 and Cul3 controlling Ci stability in Drosophila eye development}

Chan-Yen Ou, Yi-Fan Lin, Ying-Jiun Chen, et al.

Genes Dev. 2002, 16:

Access the most recent version at doi:10.1101/gad.1011402

References This article cites 62 articles, 35 of which can be accessed free at: http://genesdev.cshlp.org/content/16/18/2403.full.html\#ref-list-1

License

Email Alerting

Receive free email alerts when new articles cite this article - sign up in the box at the top Service right corner of the article or click here.

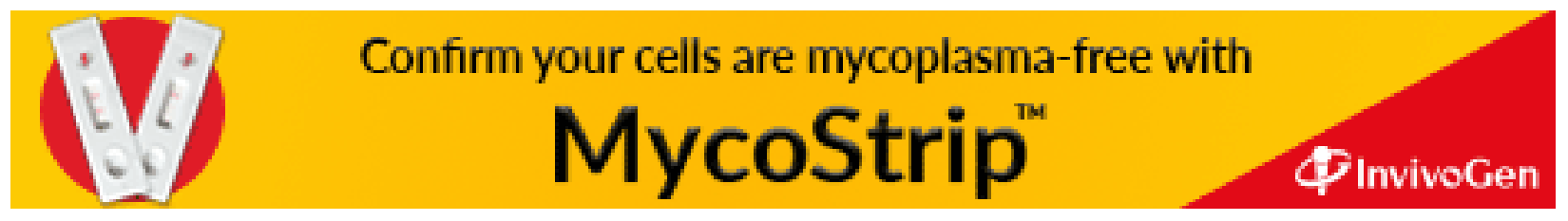

